\title{
Students Healthy Lifestyle and the Strategy of Adaptation to the University Environment
}

\author{
Farida Ishkineeva, Karina Ozerova, Simbul Ahmetova, Adelia Kaveeva
}

\begin{abstract}
The article substantiates the sociological approach to health-saving behavior as the most promising direction of strengthening students' health. Despite the wide possibilities of motivation for the health-saving behavior of students, the problems of its formation, which are due to both social and cultural characteristics, currently remain. The health of students is largely determined by the prevalence of self-preservation practices. The article discusses the problem of the relationship of students' attitudes regarding a healthy lifestyle and their self-preservation practices and the impact of the need to adapt to learning at the university. The empirical basis of the study is the materials of author's research, firstly, mass representative farrowings of students of Kazan Federal University (Kazan, Russia) $(N=12468$ in 2017 and $N=2712$ in 2018), and secondly, a series of focus groups $(N=8)$.

Sports and other physical activity, along with nutrition and sleep, are recognized by most students as important factors determining health and beauty. It is significant that it is these factors that are largely determined only by the efforts of the person himself that the students are aware of. As part of the adaptation period, students usually make new friends and gain experience in drinking. However, most students successfully cope with a difficult period and do not acquire bad habits, it is even considered not fashionable. On the contrary, students learn to plan their day wisely, find time for sports, prepare healthy meals for the whole day, and try to take care of their own psychological mood, taking responsibility for their own health.
\end{abstract}

Keywords: students, self-preserving behavior, self-destructive behavior, health-saving behavior, health, healthy lifestyle, student, youth.

\section{INTRODUCTION}

A healthy lifestyle, attention to one's own health and willingness to take care of it are factors that, along with the level of medical care and the state of the environment, are recognized as the most important conditions for maintaining the health and working capacity of the population. Focus on the value of attitudes and values of the individual in the analysis of the causes and conditions of various diseases (or, on the contrary, their absence) is a trend in recent social studies. Discussions of the scientific community are conducted around such phenomena as "self-preserving behavior", "self-preserving attitudes", "social health risks", "health-saving practices" [Vangorodskaya, 2017], as well as lifestyle, its quality and the place of health in the individual's value system.

In addition to the fact that public health is an absolute value and determines the quality of life, it also affects a

Revised Manuscript Received on November 08, 2019.

* Correspondence Author

Farida ISHKINEEVA, Kazan Federal University

Karina OZEROVA, Kazan Federal University

Simbul AHMETOVA, Kazan Federal University
Adelia KAVEEVA, Kazan Federal University

number of economic indicators - such as the cost of a health care system and labor productivity. Student youth is a resource of modern society, its educational and intellectual potential. That is why the study of ways to maintain the health of this social group is especially relevant. Students can be considered as a social group, which, on the one hand, is the subject of professional development, and on the other, the student period is a certain stage in the socio-cultural maturation of a person [Myltasova, 2017; Kanashiro, et al 2018; Kosko, \& Singh, 2019]. Thus, students also experience specific loads and conditions associated first with adaptation to the university environment, and then with the academic load, and often the need to combine training and work [Roshchin, Rudakov, 2014]. All this affects both the values of the individual as a whole and the values of health in the view of young people and their willingness to take care of him. That is why the subject of this study was the features of the student's self-preserving behavior in the context of the university environment. In this case, the university environment is understood as the institutional conditions for obtaining education - the organization of the educational process, the quality and convenience of classrooms, the quality and accessibility of infrastructure for engaging in a dispute and receiving medical care [Ishkineeva, 2018; Muyambiri, \& Chabaefe, 2018; Mussabekov, et al 2018].

\section{METHODS}

The empirical basis of the research is the materials of author's research. Firstly, these are the massive representative farrowing of students at Kazan Federal University (Kazan, Russia). The first was held in $2017(\mathrm{~N}=12468)$ and covered students of all areas of preparation and training courses, the materials of the second survey relate to 2018 and only senior students $(\mathrm{N}=2712)$. A comparison of the data reveals how student grades at the final stages of training (and, therefore, adaptation of self-preservation practices to the university environment) and the total array of students differ from each other. Secondly, the series of focus groups $(\mathrm{N}=8)$ became the method by which data were obtained for the preparation of the article. They are devoted to the transformation of attitudes to their own health during training with students in secondary courses (second and third year of study). Audio recordings of focus groups are transcribed and analyzed using the elements of "grounded theory" (open coding procedure). Based on the data obtained, the main trajectories of changes in students' self-preservation practices during their studies at the university are described.

The choice of the object of study is due to the following. KFU students are a large and diverse group, which in its demographic and social composition is typical for the students of Russia as a whole. 
The university under consideration (KFU) reproduces organizational features typical of all higher education in Russia (such as academic load, study and living conditions, measures of social support, forms of educational work).

All of the above allows us to consider it possible to extend the conclusions obtained on the used sample to the students of Russia as a whole and may be useful for preparing recommendations on creating conditions for maintaining the health of this rather large social group.

\section{RESULTS AND DISCUSSION}

Health is one of the most important capital of students, which helps them realize their potential at the university. On the one hand, young people at the university have new opportunities to maintain their health (regular medical examinations, various sports fields and events), on the other hand, the intensification of the workload and the change in lifestyle can negatively affect their physical condition. According to a survey of students of different courses, the most popular assessments of their own health are "average" and "good", and the assessment does not depend on age and course of study (on average, more than $80 \%$ do not consider their health to be poor). The results of focus groups also indicate that good health is common for students, many respondents noted that they do not think about maintaining health in their daily lives only when "it becomes so bad that it itself will not pass".

Another reason that can encourage students to think about maintaining health is the desire to look good. The vast majority of students are ready to do fitness themselves and monitor nutrition more closely for a more attractive appearance, and social networks become the sources of such settings, first of all. For many learners, bloggers are true opinion leaders that inspire respect and a desire to know sports. The main source of information on health conditions for most students is the Internet (bloggers, thematic portals). However, some students note that family members have a significant impact on their example: "I saw my father's example, he is disciplined, do morning exercises", "my parents go for tests a couple of times a year, even if nothing hurts". Another type of family influence is direct participation in maintaining the student's health (through reminders and help): "I live with my sister, and, for example, my sister does some tests, goes to the hospital and then makes me do it", "when I was at home Mom helped, I bought everything all the time, cooked breakfast, sometimes collected food at the university". However, those who undergo preventive examinations most often did this only at the insistence of relatives or acquaintances with a medical education, while the remaining respondents (more than $85 \%$ ) go to the doctor only in case of urgent need or for a formal purpose (examination for information).

When the disease occurs, students most often go to the hospital at the place of residence ( $31.3 \%$ chose this option), to a paid private clinic $(30.6 \%)$ or ask relatives and friends for advice (29\% of the students chose this option). About $24 \%$ of students who fall ill go to a student clinic. Popular "popular methods of treatment" $(20 \%)$ and search for tips on the Internet $(17.4 \%)$ are popular. The least popular is ignoring the disease, as $10.4 \%$ of respondents do. Most of all, respondents trust the quality of medical services in paid clinics or with

those doctors they trust. At the same time, virtually no one can afford regular visits to paid clinics.

Least of all trust are specialized institutions for students. The main reason is the need to wait a long time with an average level of service and quality of services. Only almost a fifth of students $(18.4 \%)$ believe that health is determined by the state of the healthcare system.

Assessing the conditions that most significantly affect health, students more often noted the influence of stress levels (74\%) and living conditions (72\%), less often ecology $(39.5 \%)$ and heredity (39\%). The significance of their own efforts to maintain health is recognized only by $29.5 \%$ of respondents. Moreover, in the sample of senior students, the proportion of those who consider themselves responsible for their physical condition is $10 \%$ higher. It is noted that the older students become, the more seriously they relate to the relationship of their mental and physical state (confirmed by both survey data and focus groups).

Recognizing the high importance of an active lifestyle, in focus groups, students often admitted that due to insufficient time for relaxation and an irrational schedule of the day, they have neither time nor energy for sports, and sometimes for cooking. In many ways, it is the university's environment (in particular, the organization of the educational process) that creates this workload: "The load is large and uneven. We have one half of the week completely free, and the second half full of lectures and seminars". On the other hand, the level of workload and stress is growing due to the need to combine work and study. As a second-year student notes, "this is not even due to my studies, but because I have a job now, two jobs, and therefore there is no time to go in for sports, there is no time to eat even normally. And how would I go to hospitals or play sports, although I would like to do this, somehow there is no time at all'. The need to combine work and study is relevant for less than half of all students surveyed: who work part-time $(17.4 \%)$, on a free schedule $(22 \%), 6.2 \%$ of students work full-time. More than half of all students $(53.6 \%)$ do not work, but they also consider the excessive level of psychological stress relevant for themselves.

The strategies with which students cope with poor health are, first of all, sleep, sports, balanced nutrition and giving up bad habits. KFU students mostly do not smoke: they never smoked $74.3 \%$, currently $18.3 \%$ smoke, $7.3 \%$ quit smoking. Another bad habit - alcohol consumption (including low strength: beer, alcoholic cocktails) - is more common among students: $60.3 \%$ of respondents drink alcohol at least once a year. Of these, $27 \%$ drink alcohol occasionally (on holidays), $21.8 \%$ - several times a month, 3.7\% - several times a week. $34.8 \%$ of respondents never or almost never drink alcohol. At the same time, as part of a free conversation, respondents note that, despite the fact that drinking and smoking is not "fashionable" now, they often encounter the normalization and romanticization of smoking in popular culture and the media: "Advocacy against smoking seems to be only on packs of cigarettes. Look, listen to modern music that young people listen to, watch these clips, films, they smoke, drink there, but smoke more often. It's like the norm".

Almost every student who participated in the focus group agreed that entering the university for him was associated with some experience of self-destructive behavior (drinking alcohol, tobacco). But over time, these practices have 
grown into a habit for only a small part of students.

Another difficulty in adapting to the university environment, which affected physical well-being, was the change in lifestyle when entering a university, this is especially true for those students who moved to study from another city and started living in a dormitory. This was especially pronounced in the psychological state: "No, the first year was harder for me because I left home, the first semester was so disgusting to me that almost every day I cried because I was not at home just to leave to another city was hard". Respondents noted that against the background of emotional depression they often caught a cold and generally felt subjectively worse. However, for the majority of respondents, the adaptation to the new status was quite successful, some were supported by new friends ("they found their people, roommates, at least I was a little scared, but when we arrived, it was difficult for everyone, but somehow we rallied"), others closely engaged in study. Over time (from the first course of study to the fourth), the grounds for anxiety have changed - if freshmen have a fear of not managing the workload, then senior students will think about their own career prospects after graduation. Student quote: "It's just that at the institute everyone is constantly thinking: oh my God, what will I do next, where will I go to work, and so on, it all pressures, annoys". At the same time, the load does not get smaller with age, just the older students learn to cope with it successfully: "Now it's easier, now we have roughly understood how to study, how to allocate time, it was more difficult in the first year".

The attitude to health has also become more meaningful among students who are studying in the third or fourth courses. Most of them go in for sports or fitness, try to eat right. It is interesting that the attitude to health is becoming more rational, independence makes some students think about the need for early prevention of diseases: "And in my university my health has improved. Because at school they just tell you what to do and eat, everything is decided for you. And when you become an adult, when you need to earn money and feed yourself, then you begin to somehow think about the topic of health. It's hard that when you are sick, you yourself have to pay for treatment. Especially the teeth. When I paid for my teeth once, after that I reconsidered my attitude to this issue". Such practices as preparing food in containers (to take healthy food for study), regular physical activity is gaining ground. But it should be noted that financial constraints impose restrictions on these practices.

\section{SUMMARY}

The results obtained on the basis of materials on studying the lifestyle of KFU students are generally consistent with foreign studies of student health. Thus, in most of these studies, university students are at risk for many health problems: mental health, alcohol and psychoactive substances, sexual harassment, poor nutrition and lack of exercise [Haase et al. 2004, Ibrahim et al. 2013, Papier et al. 2015 and others.]. The importance of family and friends in maintaining health, identified in our study, is also supported by overseas work [eg, Yubero et al. 2018]. Family relationships are very important for social, cognitive and emotional adaptation, and are also associated with quality of life, mental health and risky behavior (when such relationships are problematic). Currently, university students are experiencing ongoing maturity, which leads to increased dependence on the family. It has been shown that even when university students experience stress, they integrate better into the university when they feel support from their families [Friedlander et al. 2007]. Studies have also shown that support from friends helps to improve well-being and psychosocial adaptation. No significant gender differences were found in this study (with the exception of health care motives), but many authors abroad focus on this problem (for example, a study by Swedish students [Von Bothmer. 2005]. Swedish students have healthier habits associated with drinking and eating, but experiencing more stress. Male students showed high levels of overweight and obesity and were less interested in recommendations for nutrition and better health. This study also found differences in the motivations of students of different sexes, which is reflected in our study.

The most common practices of self-preservation behavior among KFU students are giving up bad habits. Students care about the quality of their food, go in for sports, but they do not always observe the regime of work and rest, although they know that healthy sleep and rest are necessary for good health. The main sources of ideas about what should be done to maintain health, students copy from their own parents and loved ones or from leaders on the Internet. The reason not to follow a healthy lifestyle for the studied group is the lack of time (partly due to study, to senior courses it is more connected with the combination of work and study or with activist activities).

The least common forms of health care are routine medical examinations. Students are not always clear on how to contact a budgetary medical institution; as a rule, they are not satisfied with the quality of assistance received and long lines. Students trust paid clinics more, but do not have enough resources to contact only them. In general, respondents do not have serious health problems; they are sure that they have some "margin of safety", which allows us not to consider the episodic experience of smoking or drinking alcohol as harmful. They believe that such unhealthy practices can be compensated for by sports. Students are aware of the value of health, but at this stage of their life they are ready for health-saving practices rather in order to remain physically attractive and active.

\section{CONCLUSIONS}

In general, students have a fairly deep understanding of what a healthy lifestyle is and share the belief that it is necessary to follow it. Students realize that important for health are not individual factors (such as nutrition, sleep, ecology, etc.), but their combination. Moreover, the older the respondents become, the more often they recognize the importance of a person's personal contribution to their well-being, as well as the role of the psychological state in maintaining good health. Health means, first of all, the ability to be active physically and intellectually, to have the resources to maintain a high level of energy. An obstacle for this is the unhealthy balance of work and rest that appears in the student's life as a result of the need to learn how to combine study, household duties, communication with friends and relatives. For some students, an additional burden is the need to work full time or to 
look for part-time jobs. As part of the adaptation period, students usually make new friends and gain experience in drinking. However, most students successfully cope with a difficult period and do not acquire bad habits, it is even considered not fashionable. On the contrary, students learn to plan their day wisely, find time for sports, prepare healthy meals for the whole day, and try to take care of their own psychological mood, taking responsibility for their health on themselves.

\section{ACKNOWLEDGEMENTS}

The work is performed according to the Russian Government Program of Competitive Growth of Kazan Federal University.

\section{REFERENCE}

1. S. A. Vangorodskaya, "Self-preserving behavior: the problem of the content of a concept in Russian sociology", Central Russian Journal of Social Sciences, 2017, No. $4 . \quad$ URL: https://cyberleninka.ru/article/n/samosohranitelnoe-povedenie-proble ma-soderzhaniya-ponyatiya-v-otechestvennoy-sotsiologii

2. O.V. Myltasova, "Specificity of Russian Students", Materials of the XX International Conference in Memory of prof. L.N. Kogan "Culture, personality, society in the modern world: methodology, experience of empirical research", 2017. P. 845-856.

3. S. Yu. Roshchin, V.N. Rudakov, "Combining study and work by students of Russian universities", Education Issues, 2014. No. 2. URL:https://cyberleninka.ru/article/n/sovmeschenie-ucheby-i-rabotystudentami-rossiyskih-vuzov

4. F.F. Ishkineva, "Everyday Practices of Student Self-Preservation Behavior," Kazan Social and Humanitarian Bulletin, 2018, No. 6. P. 34-38.

5. Haase, A. Steptoe, J.F. Sallis, J. Wardle. "Leisure-time physical activity in university students from 23 countries: associations with health beliefs, risk awareness, and national economic development", Preventive Medicine, 2004 Jul; 39(1), P.182-90.

6. N. Ibrahim, D. Al-Kharboush, L. El-Khatib, A. Al-Habib, D. Asali. "Prevalence and Predictors of Anxiety and Depression among Female Medical Students in King Abdulaziz University, Jeddah, Saudi Arabia”, Iranian Journal of Public Health. 2013 Jul 1; 42(7), P. 726-36.

7. K. Papier, F. Ahmed, P. Lee, J. Wiseman, "Stress and dietary behaviour among first-year university students in Australia: sex differences", Nutrition, 2015 Feb; 31(2), P. 324-30.

8. S. Yubero, R. Navarro, E. Larranaga, M. Esteban, J. Gutiérrez, M. Elche, "Health Contributing Factors in Higher Education Students: The Importance of Family and Friends", Healthcare (Basel). 2018 Dec; 6(4), P.147.

9. L.J. Friedlander, G. J. Reid, N. Shupak, R. Cribbie, "Social Support, Self-Esteem, and Stress as Predictors of Adjustment to University among First-Year Undergraduates", Journal of College Student Development, 2007, vol. 48, №3, P. 259-274.

10. M. Von Bothmer, F. Bengt, "Gender differences in health habits and in motivation for a healthy lifestyle among Swedish University students", Nursing \& health sciences, 2005, 7, P. 107-118.

11. Muyambiri, B., \& Chabaefe, N. N. The Finance-Growth Nexus in Botswana: A Multivariate Causal Linkage. Dutch Journal of Finance and Management, 2(2), (2018). 03.

12. Kanashiro, L., Ribeiro, A., Silva, D., Meirelles, P., \& Terceiro, A. Predicting Software Flaws with Low Complexity Models based on Static Analysis Data. Journal of Information Systems Engineering \& Management, 3(2), (2018). 17.

13. Kosko, K. W., \& Singh, R. Children's Coordination of Linguistic and Numeric Units in Mathematical Argumentative Writing. International Electronic Journal of Mathematics Education, 14(2), (2019). 275-291. https://doi.org/10.29333/iejme/5714

14. Mussabekov, G., Auyezov, B., Tasova, A., Sultanbekova, Z., Akhmetova, Z., \& Kozhakhmetova, G. Formation of readiness of future teachers to creative activity in school. Opción, 34(85-2), (2018). 569-599. 